\title{
Radical Holistic Intervention for Adults with Learning Disabilities who Exhibit Violent and Aggressive Behaviour
}

\author{
Jennifer Warters* \\ Living Memory Research Trust, United Kingdom
}

*Corresponding author: Jennifer Warters, Living Memory Research Trust, United Kingdom.

Received Date: May 01, 2019

Published Date: May 17, 2019

\begin{abstract}
This second paper examines an alternative holistic approach to working with adults with learning disabilities who exhibit violent and aggressive behaviour as a result of compounded trauma, due to abuse and incarceration. The orthodox approach relies upon increased staff ratio and stronger medication which can render the client hapless, helpless and unable to function. The underlying possible causative factors of what is deemed 'challenging behaviour' are discussed, together with the negative impact of trauma memories on the client's ability to adapt to environmental changes and to assimilate new information. This alternative methodology of Toning and Energy Alignment offers a radical approach to what are considered to be intractable mental health and behavioural issues. The combined methodology of energy alignment and toning enable the client to access frequencies beyond the brain to encourage maximum potential. The paper posits that consciousness is multidimensional, the higher aspects of intuitive awareness remaining unimpaired regardless of any cognitive impairment. Bio-energetic intervention seeks to restore function through a process of downward causation. Two detailed case studies verify this alternative approach as a valid and effective option, demonstrating a reduction in medication, restored confidence and self -esteem with improved communication and sociability.

Keywords: Violence; Aggression; Challenging Behaviour; Trauma; Incarceration; Learning Disability; Energy Alignment; Electromagnetic Field; Multidimensional Consciousness; Quantum Physics; Downward Causation; Energy Field; Toning; Hard Palate; Soft Palate; Alveolar Ridge; Rainbow Chakra Tones; Tongue; Ears; Sound; Syllables; Cognitive; Intuitive; Emerald; Incarceration; Trauma; Memory; Living Systems Theory; Bioenergetic; Nadis; Vibration; Yoga; Resonance; Tongue; Meridian; Post Traumatic Stress Disorder
\end{abstract}

\section{Introduction}

\section{Definition}

There is a dearth of literature discussing the impact of labelling clients with impaired cognitive function who are taken into residential care. Although defining a child or an adult with a diagnostic label can enable access to specific support provision, labelling also causes us to make assumptions. A behaviour modification approach which pays little regard to an understanding of the communication being expressed, may prove limiting.

Where behaviour is violent, challenging those responsible for prevention and intervention protocols, assumptions may limit appropriate response. When families, careers or staff are unable to cope, those from whom help is requested are often at a loss to know what to do and expensive but poor-quality care services may be funded out of the area, which further escalates the challenges and distress for everyone concerned. Placements are often a long distance from families, impacting heavily on the mental health and quality of life for both the individual for whom help is sought and their family.

In the White Paper, 'Valuing People', the Department of Health (2001) defined learning disability as:

- a significantly reduced ability to understand complex information or learn new skills (impaired intelligence)

- $\quad$ a reduced ability to cope independently (impaired social functioning)

Currently most developed countries accept a 3-part definition of learning disability: 
- $\quad$ Significant impairments in cognitive functioning

- $\quad$ Significant impairments in adaptive behaviours

- Occurs in the developmental period.

\section{Challenging behaviour}

Initially defined by Emerson in 1995 as: "Culturally abnormal behaviour(s) of such an intensity, frequency or duration that the physical safety of the person or others is likely to be placed in serious jeopardy, or behaviour which is likely to seriously limit use of, or result in the person being denied access to, ordinary community facilities".

In 2007 the Royal College of Psychiatrists defined 'challenging behaviour' similarly: "Behaviour of such an intensity, frequency or duration as to threaten the quality of life and/or the physical safety of the individual or others and is likely to lead to responses that are restrictive, aversive or result in exclusion".

Other terms used to describe the behaviour in question are 'inappropriate', 'abnormal', 'disordered', 'dysfunctional', 'problem' or 'maladaptive'. Research has demonstrated however that in some cases the behaviour is both adaptive and functional and is therefore not disordered. Many children, young people and adults with learning disabilities have no speech or very little speech and much behaviour that is deemed challenging can be seen as functioning. Challenging or potentially violent behaviour may result as a consequence of an inability to adapt to fit social needs and expectations. It can be argued that within a nurturing, responsive community or environment, the impairments would not become disabilities [1].

The current term 'challenging behaviour' reminds professionals, staff and policy makers that such behaviour challenges us to seek ways of offering alternative solutions. We must therefore understand the cause of the behaviour that challenges. It may indicate an unmet need and those who cannot express themselves verbally will find other ways of making their feelings apparent.

\section{Environmental factors}

The setting in which behaviours occur can influence whether the behaviour is considered by professionals to be challenging. For example, if someone with severe disabilities frequently wakes through the night, and wanders about the house, it would not be considered challenging if there was adequate night staff to accommodate the individual [2].

Studies in hospital/institutional environments have produced higher figures of individuals with behaviour that challenges because of aspects of that environment which may cause an escalation of distress communicated through behaviour. Instead of focussing upon the label as a diagnosis of the person, we might more usefully consider possible changes required to lessen the impact of the environment on the individual in question.

Some care environments inevitably increase the likelihood of behaviour that challenges. This includes environments where social interaction is limited and opportunities for choice are severely restricted. Unresponsive or unpredictable behaviour may be a consequence of neglect and abuse. Those with limited intellectual capacity may be trapped in the emotional turmoil of daily life and routine, the lack of control of life situations, circumstances and environment, expressed as anxiety, depression, restlessness and rage.

\section{Post-traumatic stress}

It has been supposed for many years that traumatic experiences may lead to aggressive and disturbed behaviour. However, it is shocking to note that it has only recently been reliably established through studies, that those who have suffered abuse or have experienced a traumatic life event may suffer from PTSD (post traumatic stress disorder) or have significantly more mental health requirements. A very consistent pattern emerged of significantly fewer behaviours that challenge arising before the traumatic event and significantly raised levels just after the traumatic event, with some improvement years later.

Today, post-traumatic stress disorder is recognized as a crisis response which can result from any serious trauma including psychological or physical abuse with long term and often permanent consequences. The symptoms include reliving the trauma as flashbacks which may persist for years. An adult with cognitive impairment has less ability to verbally communicate negative experiences effectively or to develop coping strategies and therefore, 'acting out' their fear, anger and frustration, is the only outlet. Emotional disconnection frequently ensues, referred to as 'emotional numbing'.

\section{Memory, perception and repetitive behaviour}

Our view of the world is restricted by our belief system and trauma memories can formulate prejudices from which we make our choices, influenced by past experiences. These may have no bearing on our present circumstances but can skew perception. Such memories can be traced as causative factors in intractable mental health and behavioural issues.

Adults with a learning disability often find themselves at the receiving end of failed communication and stressful situations, which continually undermine their ability to process their thoughts and make appropriate decisions and choices because they may feel pressured and overwhelmed emotionally. 'Triggered memory of a previous trauma can release overwhelming emotion because the body never forgets, and memories and feelings are stored as reliably as data on a computer always ready to be recalled by the click of a mouse'. Rhodes J [3] As a result, the individual may be caught in a loop of triggered repetitive behaviour. Healing can only take place if stress levels are reduced to allow unhelpful and often painful memories of experience to be dissolved and replaced by a new positive experiences and outcomes.

\section{Energetic imprints}

Memory is imprinted energetically within the electromagnetic field. Negative experience creates disturbance.... within the 
dynamic flow resulting in impaired flow. This manifests in physical symptoms of dis-order and dis-ease and may also manifest as impaired communication and behaviour because the flow of the subtle energy within the electromagnetic field is interrupted by the energetic imprints.

'Imprints of memories from the past are held within the subtle energy field (electromagnetic field,). 'Imprinted memories are also downloaded at a sub molecular level to the cellular body where they continue to impact on physiology in a negative manner. Subconscious memories impact upon the cognitive and sensory vibratory fields within our subtle energy system as energetic imprints, holding the residual blueprint of past experience. Memories of past experience are continually being triggered and reinforced by events and interactions in our daily life, which give rise to repetitive patterns of unconscious automatic behavioural response [4]. In order for harmonious flow to be restored, a process of safe and effective -energetic release is required.

\section{Methodology}

\section{Subtle energy system}

To fully understand an holistic perspective, we must acknowledge both the physical body system, the focus of orthodox medicine and the multi-levelled subtle energy system, recognised and mapped since ancient times, which mirrors the physical anatomy and interfaces with the physical body. Medical science views the brain as the seat of consciousness, while integrative medicine acknowledges an interconnected source beyond the brain. Through a process of 'downward causation' Goswami A [5] the cognitive processes of brain anatomy are linked to mental faculties, directed from the individual higher consciousness. It is this mental processing which is impaired in those described as having 'learning disabilities' because of cognitive impairment which may or may not result in violence or challenging behaviour. A transportation system of a complex network of meridian channels and minor and major chakras link to major organs and body systems. In yogic philosophy there are some 72,000 nadis (energy channels) flowing through the body, forming interlinking connections within the anatomical structure of the subtle energy system.

The subtle energy system, nourishes and rejuvenates the physical body and is recognised as the life force [6]. With increased awareness, the higher centres are accessed, changing perception and increasing empathy and discernment.

The principle behind energy balancing, is 'energy follows thought', There is an immediate energetic response to wherever we place our attention. When we understand the process of energy flow, we can begin to understand how physical symptoms and behaviour are influenced by the thoughts and feelings associated with the memory of past experience [2].

Through the pioneering research of developmental biologist, Bruce Lipton and neuroscientist and pharmacologist, Candace Pert we are given proof that we can affect our immune system and our brain chemistry by what we are thinking and feeling because every thought and emotion has a particular vibratory frequency that creates a chemical reaction within the brain. Sound is the expression of thought and feeling, whereas energy alignment restores harmony, encouraging more positive self-expression i.e. a sound vibration which will have a positive effect on our lives. Toning provides a specific focused vibration $[7,8]$.

\section{Toning}

A full explanation of toning is given in Paper 1 Adults with Learning Disabilities [2]. The universe is composed of vibration and therefore we can harness sound as a potent tool to maintain homeostasis. Toning is an ancient and powerful method of healing ...with the voice which draws upon the body's inbuilt systems of self-healing to facilitate the release of tension through the positive and focused use of voice. This is a simple yet radical approach to harmonising frequencies in the brain, the physical body and the subtle energy system and is based on the premise that specific sound syllables (tones) create a resonance of sound that causes a chain reaction of cellular communication where chemical messengers alter the composition of chemical fluids in the brain. As energetic pathways are harmonised, the chemical composition of the brain is re balanced and one's outlook on life is changed.

The human mouth represents an oral resonating chamber for vocal sound and the roof of the mouth houses 84 meridian points, which are interconnecting contact points for the dissemination of energetic flow throughout the physical body system. The movement of the tongue stimulates these meridian points. To understand this action, we can use the tip of the tongue to feel the different surfaces within the mouth, by tracing a line from the alveolar ridge just behind the upper front teeth, to the hard palate (the roof of the mouth) and if we curl the tip of the tongue back, we are able to touch the soft palate. 'Every time we make a tone, we initiate a new vibration which circulates energy throughout the body' [9].

The Toning and Alignment programme uses a specific chakra toning system which offers a unique system of eight vocal tones. Each tone resonates with a specific chakra (Energy Centre) and corresponds to a specific anatomical area of the body.

\section{Emerald alignment}

See Appendix for an illustrated description of the Emerald Alignment method which is used in this therapeutic approach. A full explanation of the principle of alignment with reference to this specific alignment is given in paper 1 [2].

Regular alignment strengthens the immune and neurological systems by reducing the production of stress hormones. A plethora of scientific research into psychophysiological stress recovery promotes 'green exercise' and 'green spaces' within urban development e.g. $[10,11]$.

Detailed Case studies validate the positive impact of focusing on the accelerated frequency of the emerald green ray to elevate the vibratory frequency of the physical body through magnetic attraction. Bio-energetic interaction explains the holistic 
integration of body, mind and spirit where alignment of the atoms and molecules of the subtle energy system are brought to coherence, balance and harmony.

\section{Adapt and survive}

Living Systems Theory describes the interrelationship and interdependence of all living systems 'any change in the state of one quanta would be reflected in the state of all quanta' [12]. Quanta describes the smallest possible discrete unit of any physical property, such as energy or matter.

A General systems theory, has emerged from the life sciences, bringing fresh evidence to confirm ancient, indigenous teachings that every system is something that is simultaneously a whole and a part. Living systems are comprised of subsystems and are simultaneously part of a larger system. If our changing behaviours are not compatible with the challenges we face, and do not achieve a new balance with them, the positive feedback loop gets out of control eventually leading to systems breakdown.

Thus, holons (something that is simultaneously a whole and a part) form "nested hierarchies," systems within systems, circuits within circuits, fields within fields. for example -atom to molecule, cell to organ, person to family etc. Systems can self-regulate to compensate for changing conditions in their environment e.g. how we maintain our body temperature. However, when challenges from the environment persist, systems can fall apart, or they can adapt by reorganising themselves around new, more responsive norms. However, if our behaviours are not compatible with the challenges we face, and do not achieve a new balance with them, the positive feedback loop gets out of control leading eventually to systems breakdown.

Understanding how all living systems 'work', maintain themselves, develop and change helps to throw some light on the struggles experienced by those whose behaviour is deemed challenging to others.

\section{Case Studies}

The following case studies are offered as examples of successful outcomes. Throughout the therapy process with my clients, I received the benefit of the understanding of my two colleagues on The Living Memory Research Trust, Carol Lamb, an experienced Past Life and Trauma Therapist and Sandra Lamb, a Numerologist and Medical Astrologer.

\section{Client A}

\section{Man aged 39 years}

7th child in family of seven children

Restricted oxygen at birth/diagnosis of learning disability

History: When Client A was 13 years old, his father died and because his mother was unable to cope singlehandedly with Client A and his 6 older siblings, a decision was made to place Client A in a large asylum hospital at the age of 14 years, where he remained for the next 9 years. Family visiting was initially spasmodic and this dwindled to lack of family contact because of Client A's 'unpredictable violent behaviour'. Written evidence supports the probability that Client A was physically and sexually abused by other residents.

At the age of 23, Client A was moved to shared-living accommodation, with 5 other men where his violent behaviour ('challenging behaviour') escalated. He was then moved into a flat with one other man who also had 'challenging behaviour'. Ongoing disillusionment with the system and a lack of managerial support prompted staff shortages. Finally, when Client A was 31 years, a leaking boiler and toxic fumes prompted a move to another residential home under close supervision with 6 other men. Client A's violent behaviour again escalated and he was reportedly 'lashing out' at other residents and staff.

Within 12 months, at the age of 32 years, Client A was moved to the basement of large (ex-Workhouse) hospital and was increasingly sedated because of violent outbursts. A Secure Unit was recommended by hospital staff. However, those staff members who were aware of Client A's history fought against Client A's move to a Secure Unit and Client A was returned to his previous accommodation with 6 other men at the age of 33 years.

For the next three years, Client A's challenging behaviour continued and he is reported to have 'assaulted all those who showed him kindness.' He refused to go out and an exhausted staff were at a loss and felt that accommodation tailored to Client's needs was required in order to prevent further stress induced staff shortages and Client A's spiralling decline.

At the age of 36, Client A was moved into his own house supported by a staff team of 10 (both male and female). Two members of staff were on duty at all times. It was at this time that Client A was referred to the clinician researcher's funded holistic therapy project.

\section{Presenting behaviour in the home}

- Anxious on waking

- Behaviour worsens after breakfast

- $\quad$ Refuses to share

- $\quad$ Smashes CD player when frustrated

- $\quad$ Fear of water

- Ongoing bowel problems, alternating diarrhoea and constipation.

- Poor hand function, difficulty with fine motor skills, pincer grasp and grasping and holding on to objects.

- $\quad$ Requires help with needs i.e. toileting/dressing.

- $\quad$ Limited communication

- $\quad$ Disconnected speech

- $\quad$ Able to use significant key words i.e. naming of objects, food and action words e.g. stop, go, run, eat etc. 
- Using previously learnt phrases inappropriately.

- $\quad$ Repeating questions but does not answer the question.

- If given choices, takes the last option and then becomes frustrated if it is not what he wants.

- $\quad$ Restricted articulation (omitting specific speech sounds / consonants), which means that Client A's speech is difficult to understand when there are no contextual clues.

- He becomes frustrated and angry if not understood

- $\quad$ No apparent understanding of the concept of time.

\section{Behaviour when angry}

- $\quad$ Client A rushes towards a member of staff with arms raised.

- $\quad$ Two staff members intercept client and link an arm tightly on either side.

- $\quad$ Client then drops to his knees spontaneously.

- $\quad$ Client A turns very pale and repeats a varying sequence of numbers between 1 and 5 .

Therapist attended meetings with staff and carers to explain the holistic approach and the methods used i.e. energetic alignment and vocal toning and explained why.

- $\quad$ Stressed importance of staff team using the energy alignment themselves to seal and strengthen their electromagnetic field.

- $\quad$ Staff Team to integrate the energy alignment exercise into Client A's Care Plan.

- Staff were keen to help the client and eager to try new ways of working.

- Some members of staff were sceptical at first but gradually with patience, a good relationship of trust was built up.

- $\quad$ Therapist requested that staff members remained seated and silent in the therapy session, to allow the therapist to be in control of each session.

- $\quad$ However, if Client A became angry or violent, staff would follow their client safety procedures.

As the therapy sessions progressed, the staff could see the transformation, and this resolved a lot of their worries and staff members took a keen interest in Client A's progress.

\section{Therapy offered}

- Weekly sessions of 30 minutes duration

- One staff member to remain in the room with client. The other staff member remained in the waiting room outside.

- $\quad$ Provide structure, all sessions opened and closed with therapist talking client through an energy alignment (Emerald Alignment)
- Offering choices, no prompting of client in choice making.

- Therapist responding and developing but not initiating.

- If client indicates that he wants to leave by walking towards the door, he is able to leave at any time during the session.

\section{Available choices for client}

- $\quad$ Chair to sit on

- Water to pour and glasses to drink from.

- Water can be offered to others.

- Swathe of emerald green and blue material hung at the window to mirror the colours of the energy alignment exercise.

- Box of coloured silk material corresponding to the seven colours on the rainbow spectrum.

- Therapist vocalises the corresponding tone if the client selects a specific colour of material from the box.

Therapist sang a wide range of short repetitive songs with easy to remember choruses e.g. 'My Bonny Lies Over the Ocean,' 'Nick, Nack Paddy Whack', folk songs and negro spirituals. The client's pattern of falling to his knees and his preference for negro spirituals supported an initial intuitive impression of an energetic imprint of subjugation and slavery originating in pre-birth trauma memory. 'When imprinted memory is triggered and thus brought into conscious awareness, we experience the emotional connection whether positive or negative and this can also trigger a positional memory. Mainstream medical science only recognizes current life experience, however the numerous evidential case studies now collated by eminent psychiatrists, psychologists and others, present irrefutable evidence for the continuity of the soul and its ability to recall previous incarnations [9].

\section{Activity suggested to replace entrenched behaviour pattern}

- Suggested that Staff work towards backing off from linking arms with Client A to loosen their arm hold and stand either side, to break the pattern of the client falling to his knees.

- Requested that the staff find a positive creative activity to share with the client that involved kneeling and doing something he enjoyed doing, which would replace the client's distress pattern of falling to his knees i.e. Drawing with coloured chalks while kneeling on the floor, either inside or outside on the pavement and allowing the rain to wash it away.

- $\quad$ Kneeling to plant flowers in tubs.

- $\quad$ The staff to work towards not linking arms with the client when he is in attack mode because this pre-empted his falling to his knees.

\section{Maxim during the therapy sessions}

- Have no expectations

- Make no assumptions 
- Wait, watch and listen

- Follow client's lead.

\section{Progress After 3 Weeks}

- $\quad$ Client A spontaneously selected a specific colour of material from a box and gave it to the therapist who placed it over a bamboo screen.

- $\quad$ Client A repeated the corresponding vocal tone after the therapist.

- In response to hearing a specific vocal tone, Client A selected the corresponding colour and hung it over the bamboo screen.

- $\quad$ Client joined in with a diverse selection of short repetitive songs.

\section{Progress after 1 month}

- $\quad$ Client began to select a specific colour of material without prompting and spontaneously made the corresponding tone.

- $\quad$ Client A hung each piece of material over a bamboo screen that was in the room.

- $\quad$ Client A spontaneously singing his preferred choice of song. Negro spirituals 'Pick a Bale of Cotton 'and 'My Curly Headed Baby' were favourites.

\section{Progress after 2 months}

- $\quad$ Each chakra tone links to a specific anatomical area of the body. and in subsequent sessions, when the therapist vocalised specific tones, the client was able to indicate where on his body he felt the vibration of the tone, e.g. pointing to knees, chest or forehead etc. (The areas identified, corresponded with blocked energy patterns.)

- $\quad$ Client wanting to include the member of staff in the therapy session and wanting member of staff to tone with him (personal empowerment -becoming the teacher)

- $\quad$ Praising staff members for their attempts to tone with him.

- Becoming more empathic in session: if toning caused member of staff to cough, without being asked, the client poured them a glass of water without spilling it.

- Improved communication.

- $\quad$ Said 'Well done' if he was impressed with staff member's toning.

- $\quad$ Able to repeat the system of 8 chakra tones without prompting.

- $\quad$ Taking appropriate control of session and not abusing his role.

\section{Positive outcomes after 3 months}

- Greatly reduced medication
- $\quad$ Depression lifting

- $\quad$ Reduced episodes of violent behaviour

- $\quad$ Client more confident and sociable.

- Using vocal tones spontaneously at home.

- $\quad$ Attending to own toilet needs.

- Improved bowel function.

- $\quad$ Client A using care staff names spontaneously

- $\quad$ Exhibits renewed confidence in his posture and bearing i.e. Shoulders back, head up, back straight.

- Communication is more fluid

- Articulation is clearer.

- Vocabulary has increased.

- $\quad$ Client finds it easier to get his message across because more staff are able to understand what he is saying.

- $\quad$ Connecting more with family members

- $\quad$ Now making appropriate choices and no longer chooses the last option offered.

- $\quad$ Enjoys the therapy sessions and Client A shouts a greeting as he approaches the stairs on arrival.

- When vocal tones were made, Client A spontaneously named and touched the body part where he felt the vibration of the tone i.e. knee and forehead.

- Beginning to use complex grammatical structures and questions i.e. 'Hey, how are you mate, you coming tonight?'

- Making appropriate choices, not just repeating question.

- $\quad$ Respectful of therapist and space.

- Able to name his feelings when asked e.g. 'I'm not alright, angry, tired etc

- If Client A wanted to terminate the session early, he said, 'Had enough' and left the room.

*Staff members observing the sessions commented that Client A was enjoying himself and was spontaneously choosing the activities he enjoyed. Support staff had not observed this before.

Conclusion at 6 months: Client A spontaneously made the tone that resonates with the heart chakra for a member of staff when she sat next to him after a period of absence because of the loss of a parent. The client's action made her cry and demonstrated a developing ability to empathise and to understand the feelings of another, where he had previously merely shown anger and frustration.

The energy alignment exercise (Emerald Alignment) was written into care plans and each staff member took responsibility for aligning Client A and themselves when they come on duty. This has proved a successful way for staff members and clients alike to 
release any tension or anxiety they may have been feeling prior to engaging with each other [14].

Client A continued to sing a favourite negro spiritual 'Pick a Bale of Cotton' at home. Staff members reported that Client A had begun to make up his own words to the same tune to accompany his everyday routines at home e.g.

'Going to jump down, have a bath, shave, put my shoes on,

Going to jump down, turn around, have a bath today. 'An example of self-empowerment to eradicate an imprinted memory pattern of subjugation. Current research into the continuity of consciousness investigates the possibility of memory of other lives. Whatever the origin, the memory of subjugation for this client was erased by the combined approach of energy alignment and toning.

Use of language and vocabulary improved. As Client A developed his ability to communicate, he was more able to make sense of his world and to communicate this to others. This also enabled him to rationalise and to make sense of his environment and begin to adapt to any changes taking place.

Client A's family began to resume their visits after a long absence because Client A was calmer, and his speech was clearer.

*Client A became angry and went into his anger pattern on only one occasion in the therapy session. This happened when a new member of staff neglected to observe the rule of non-interference in the session and intervened with Client A to try and stop him when he got up from his chair to pour himself a drink of water. Client $\mathrm{A}$ shouted at the member of staff and the 2nd member of staff entered the room before Client A's behaviour could escalate.

Funding was discontinued after 6 months but Client A continued to fund his own sessions for a further six months. The client's key worker trained in the energy alignment and toning programme to gain a deeper understanding of energy alignment and the principles of healing in order to sustain the client's holistic healing program.

\section{Client B}

Male - aged 46 years

History: The youngest of four children, Client B was reported to have been consistently aggressive and violent towards family members. When he exhibited aggressive behaviour as a child, Client B was shut in a cupboard by his father.

At the age of 3 years he entered a mainstream nursery but reportedly consistently attacked and bullied the other children. He was subsequently removed from mainstream school and placed in a school attached to a large asylum hospital where he was placed for weekend respite. He continually asked to be taken home. At the age of 6 years, Client B was given a permanent placement in the asylum hospital, where he spent many years with little contact from family members because of his spiralling violent behaviour.

At the age of 10 years, Client B was described by hospital staff as 'a frightened little boy' who continually asked to go home. He 'craved affection' and continually sought reassurance from hospital staff that he had been good. He was reportedly bullied by older residents but attacked the staff rather than the perpetrator. When he was 15 years old, Client A's behaviour deteriorated further and during violent episodes he threw tables and smashed windows.

At the age of 23 years, foster parents were found but the placement was brief because of Client B's violent behaviour towards them. He was returned to the asylum hospital. Documentation states that he required to be in the company of assertive staff members because he 'stalked vulnerable staff' and would attack their eyes with his finger nails, if the opportunity arose.

Client B's behaviour deteriorated into self-harming, slapping his own face with his flat hand when frustrated.

In his middle-twenties, Client B was discharged from the long stay hospital and moved into residential accommodation with 5 other men who had similar problems. He received 24-hour supervision from a committed staff care team.

\section{Presenting behaviour in residential care}

- Violent and aggressive outburst uses his nails to scratch those he attacked.

- $\quad$ Attacks the eyes of staff members with his fingernails, has caused severe injuries.

- As frustration and anger builds, his facial expression changes - lip curls and client snarls.

- $\quad$ Afraid of dogs, saying 'dogs bite'. Before placement in the long-stay hospital, he lived with his family on a farm and to keep him away from the dogs, his father had told him that dogs bite.

- Afraid of the dark and requires a light on throughout the night.

- $\quad$ Carries three soft toys: Two dogs and a monkey.

- Using single words, familiar phrases, names familiar objects.

- Does not use the names of members of staff.

- $\quad$ Slapping own cheek with flat hand

- Spends very little time in his own room.

- Poor bowel function

\section{Reason for referral to holistic therapist}

- To reduce stress levels.

- $\quad$ Requires help to make choices, in order to gain some control over his daily life.

- $\quad$ Client requires help to express his feelings verbally rather than 'acting them out.

- $\quad$ Needs to develop language and improve communication, in order to progress from use of single words to longer phrases and sentences. 
- $\quad$ Requires help to manage his emotions and eliminate aggressive behaviour to improve interaction and relationships with residential staff.

- $\quad$ Care staff require training in coping strategies.

\section{Therapist observations}

Client B's room is a visually over-stimulating environment

- $\quad$ Striped multi-coloured bed cover in burgundy and brown,

- $\quad$ Flowered chair cover in reds and blues

- $\quad$ Patterned multi-coloured curtains

- $\quad$ Clutter on all available surfaces

- $\quad$ Limited cupboard space to store possessions

- $\quad$ Limited shelf space

- $\quad$ Beige-coloured dried flowers in the fireplace.

Setting the groundwork: Therapist called a meeting with care staff to explain her holistic approach i.e. energetic alignment and vocal toning and explained the rationale underpinning this approach. It was suggested that a peaceful space should be created (bedroom sanctuary) for the client to withdraw to in times of need and to help him to de-escalate his aggressive behaviour. The therapist stressed the importance of establishing the client's colour preferences for furnishings and bed linen. It was agreed to share ideas and work together as a team for the benefit of the client.

Negative assumptions of staff members that Client B had no understanding of colour and would therefore be unable to make a choice of colour for his room were addressed. Care staff were reminded that negative assumptions create low expectations of ability, inhibiting potential.

At the initial meeting with Client B, the therapist asked 'What is your favourite colour? Without hesitation he replied 'blue'. Staff were surprised at this response but admitted that they had never asked him this question. With the best intentions, staff members anticipate the needs of their clients and in an institutional setting where meals, snacks and breaks are regimented, choice making is limited, inhibiting the client's ability to make choices and develop communication.

\section{Therapeutic intervention}

- It was important that the staff team used the energy alignment themselves to stabilise their emotions and to seal, protect and strengthen their electromagnetic field. (see explanation of the Emerald Alignment in Methodology section)

- Regular alignment practice will reduce and stabilise emotional response to external events and reduce the likelihood of triggering an anxious or angry response from another because we feel calmer in the company of someone who is relaxed and whose response we can predict.

- $\quad$ Staff Team agreed to integrate the Emerald Alignment method into Client B's care plan for daily practice.
- $\quad$ To create a peaceful and stress-free sanctuary (client's bedroom) for the client to withdraw to in times of need.

- $\quad$ To determine Client B's musical preferences by offering a variety of musical choices and waiting and watching for the client's response.

- $\quad$ Place CD player in the room to allow the client to play his music at a time of his choosing.

- $\quad$ Staff members encouraged to use ongoing descriptive language to accompany shared activities rather than issuing commands and instructions.

- Staff encouraged to respond to all client's positive attempts to communicate and if client uses a single word to communicate, staff to extend his language by modelling a longer sentence in response, which includes the word the client used e.g. Client- 'Car? 'Response- 'Yes, we are going in the car to the Garden Centre'

- To create a bedroom sanctuary removing patterned curtains, chair covers and bed linen which may be visually overstimulating.

- $\quad$ To replace the above with pastel shades chosen by client.

- Confirm client's colour preference, by offering him a choice of fabrics in clear rainbow colours and waiting for his unprompted response.

- $\quad$ Create cupboards for storage

- $\quad$ Surfaces to be kept clear of clutter

- $\quad$ Replace dried flowers with fresh flowers and green plants to oxygenate room.

- To recognize significant anniversary dates and cycles, which may be associated with a deterioration in the client's mood e.g. date when first placed in Care, Christmas, Birthdays, disappointments, traumatic events, loss, grief etc.

- $\quad$ The date and month of the event is relevant because the anniversary of the event may trigger the emotion of the original event and impact at a subtle energetic and physical level [11]. If unresolved, painful feelings associated with past events, may be re-experienced cyclically.

- It is important not to make assumptions about the associated memory of a specific event because a happy time for one person may be an unhappy time for another.

- Attuning to the client's mood and encouraging the client to express his feelings appropriately aids the process of release,

- Allow emotional release, acknowledging that tears are healing.

- Introduce an enjoyable activity to replace an unhappy memory.

- Take photographs as a reminder. 


\section{Outcome of therapeutic intervention}

Energy alignment programme: Staff members noted that aligning their energy prior to contact with Client B. had a positive effect. The Emerald Alignment programme was integrated into his care plan and practiced twice a day (morning and evening) with the client. The Emerald Alignment would be used more often with client, if staff deemed it necessary.

Personal empowerment: Staff members re-painted client's room in pale blue- chosen by the client from paint cards. Shopping excursions created enjoyable socialization, enabling the client to choose personal items for his room. Client was taken to a department store and chose sky blue curtains and bed linen decorated with dolphins. He is increasingly using his room as a refuge, withdrawing unprompted for quiet time for longer periods during the day.

Toning: Staff members are demonstrating specific vocal tones with the client on a daily basis as recommended by the therapist, reporting that toning together helps the client to relax. The client is feeling the beneficial effects and can be heard continuing to use the tones when alone in his room.

Environment: Staff built cupboard for storage in client's room and encourage him to remove clutter from surfaces. Windows are opened to improve ventilation and dried flowers have been replaced by fresh flowers and green plants.

Communication and social skills: Staff noted that the client's communication is improving. He is spontaneously using names of staff members and longer sentences and phrases to express his needs, rather than single words. Client B became more sociable with other residents and willingly shared his sweets and biscuits without being prompted. On previous occasions he had refused to do this.

Medical: The client's bowel function has improved as a result of the energy alignment programme which has reduced stress and tension. Medication has been reduced in line with the Care plan.

Conclusion: When Client B's behaviour improved and he became less aggressive and more able to express himself, the therapist met with his younger sister, who tentatively resumed contact with her brother. Her visits progressed to supervised meetings in local cafes and eventually to supervised home visits at both his home and hers. Client B's sister enjoyed tap dancing and when visiting her brother's residential home, she brought her tap shoes to show him. On one occasion she demonstrated a tap dance she had been learning and her brother excitedly joined in. Care staff purchased some tap shoes for him so that she could teach him some steps.

After a six -month period of monthly visits of support and monitoring, the support staff with whom the therapist had worked closely, attended a workshop on holistic intervention for impaired communication and in the following monthly review with the therapist, stated that they both felt confident in continuing without ongoing monthly monitoring and support. Further contact ceased.
Postscript: After a period of two years had lapsed, the therapist saw Client B again in the local town with one female member of staff, they were in conversation, deliberating where to go for a cup of tea. The therapist was delighted to see that the client was no longer conspicuously walking along the pavement with a male and female member of staff either side of him, policing his every move and reaction as before and appeared relaxed and happy.

\section{Conclusion}

There is increasing global awareness that in many cases, alternative and complementary therapies may be more conducive to health than conventional ones. Holistic therapists and health care professionals are therefore charged with finding another way of working with those with intractable conditions who are shut away from society and for whom limited help is available.

This work is important in maintaining stability of placements and preventing further destabilising moves, which frequently exacerbate stress and accelerate mental deterioration e.g. Client A.

Living Systems Theory posits the belief that all life is process and our ability to function is dependent on input, throughput and output. Are we able to adapt to changing input (information received)? Throughput relates to our ability to understand and assimilate the information received and output demonstrates the ability to use what has been processed to adapt to the changing environment. An individual suffering from post traumatic stress disorder and $\backslash$ or impaired cognitive ability will be unable to process his or her experiences unless the underlying emotions are first addressed.

The shifts made in the therapy programme altered the individual's perception of the world around them and changed their view of those who inhabited their immediate environment. The detailed case studies demonstrate that with patience, kindness and cooperation, 'we may be able to restore: our self-esteem, our self-worth, our self-confidence, our wellbeing and our safety, which stem directly from the way we think of ourselves in the world' [1519].

\section{Acknowledgement}

None.

\section{Conflict of Interest}

Author declare no conflict of interest.

\section{References}

1. (2003) National Institute for Health and Care Excellence: Clinical Guidelines.

2. Warters J (2018) Paper 1: A Radical Approach to Working with Adults with Learning Disabilities to Encourage Optimum Potential. Combining the Human Voice (Toning) with Energy Field Alignment to Access Higher Intuitive Pathways Beyond the Cognitive Faculties.

3. Rhodes J (2018) Fire on All Sides. Quercus Editions, UK.

4. Lamb C (2017) Human Consciousness Ephemeral and Material Structure.

5. Goswami A (2017) The Everything Answer. Hampton Roads Publishing, US. 
6. Lamb C (2015) Anatomy of the Human Energy Field. Epiphany Press, UK.

7. Lipton B (2008) The Biology of Belief. Hay House, UK.

8. Pert CB (1999) Molecules of Emotion. Simon \& Schuster, UK.

9. Mathur PM (2017) Advantage Mantra in Yoga.

10. Hartig T, Evans GW, Jamner LD, Davis DS, Garling T (2003) Tracking restoration in natural and urban field settings. Journal of Environmental Psychology 23(2):109-123.

11. Pretty J, Peacock J, Sellens M, Griffin M (2005) The mental and physical health outcomes of green exercise. International J Environ Health Res 15(5): 319-337.

12. Laszlo E. The Immortal Mind Inner Traditions.

13. Lamb C, Warters J (2018) Human Consciousness Part 2: Multifaceted Aspects of Human Consciousness, Reincarnation and Past Life Memories in Childhood.
14. Self Help Through Emerald Alignment: Living memory Research Trust. 15. Braden G (2017) Human by Design. Hay House, US.

16. Lamb C (2018) The Phenomena of Samskaras (Energetic Imprints of Unresolved Past Life Experiences) Manifesting as Causative Factors in Behaviour, Linking Soul Group Consciousness.

17. Iyenga BKS (2014) Yoga: The Path to Holistic Health. Dorling Kindersley, London.

18. Browne C, Smith IC (2018) Psychological interventions for anger and aggression in people with intellectual disabilities in forensic services. Aggression and Violent Behavior 39: 1-14.

19. (2006) Yoga of Sound Russill Paul Healing and Enlightenment Through the Sacred Practice of Mantra. New World Library, US. 